\title{
De espacio ameno a territorio amenazante: la representación de la tierra de Chile en Desengaño y reparo de la guerra del reino de Chile (1614), de Alonso González de Nájera ${ }^{i}$
}

Recibido: 17 de agosto 2017

Miguel Donoso Rodríguez

Universidad de los Andes, Chile

mdonoso@uandes.cl

Aceptado: 3 de marzo 2018

\section{Resumen:}

Las crónicas indianas suelen idealizar el espacio que describen como una forma de reclamo, para mostrar las bondades del territorio. Asimismo, pueden presentar esa naturaleza como agreste e indómita, para explicar las dificultades de la conquista en esos lugares. Un buen ejemplo de esto se puede apreciar en Desengaño y reparo de la guerra del reino de Chile (1614), de Alonso González de Nájera, obra heterogénea que mezcla el tratado natural y moral del territorio austral y sus gentes con la crónica o relación de sucesos; tratado de cautiverio y a la vez arbitrio o memorial para ganar la guerra de Arauco. El espacio juega aquí un rol vital: por una parte el autor lo utiliza para hacer alarde de las bellezas del lejano territorio de Chile, y por la otra muestra cómo lo agreste y salvaje de la tierra proporciona a los indígenas ventajas insuperables en la guerra.

Palabras clave: Alonso González de Nájera; Desengaño y reparo de la guerra del Reino de Chile; crónicas chilenas; espacio ameno-agreste, arbitrismo.

From space to threatening territory: the representation of the land of Chile in Desengaño and reparo de la guerra del reino de Chile (1614), by Alonso González de Nájera

\section{Abstract:}

Indian Chronicles usually idealize the space they describe as a form of reclamation, to show the benefits of the territory. Also, they can present Nature as wild and untamed so to explain the difficulties of Conquest. A good example of this is Desengaño y reparo de la guerra del reino de Chile (1614), by Alonso González

\section{(C) $(\otimes \odot)$}

La Revista Estudios es editada por la Universidad de Costa Rica y se distribuye bajo una Licencia Creative Commons Atribución-NoComercial-CompartirIgual 3.0 Costa Rica. Para más información envíe un mensaje a 
Especial: Naturaleza amena y naturaleza agreste en las letras hispánicas de Nájera, a heterogeneous work that mixes the natural and moral treatise of the Austral territory and its people with the chronicle or narrative of events; treatise of captivity but at the same time means or memorial to win the Arauco war. Space plays a vital role here: on the one hand, the author uses it to flaunt the beauties of the distant territory of Chile; on the other shows how the rough and wild land provides the Indians with insurmountable advantages in war.

Keywords: Alonso González de Nájera; Desengaño y reparo de la guerra del reino de Chile; Chilean chronicles; pleasant-rustic space, arbitrismo.

No resulta fácil encasillar un texto tan heterogéneo como es el de Alonso González de Nájera. Su Desengaño y reparo de la guerra del reino de Chile, terminado de redactar en 1614 en la Toscana por este maestre de campo natural de Cuenca, parece pertenecer a un género indeterminado, tal como ocurre con un sinnúmero de textos coloniales. Por un lado, es indudable que esta obra posee elementos propios de la historia natural y moral, cuya escritura promovió la Corona a partir de las ordenanzas reales del último tercio del siglo XVI, como se puede apreciar en varias secciones del Libro primero. Pero, por otra parte, el texto se aproxima también a la crónica o relación de sucesos: así en los relatos de la derrota española en Curalaba y la posterior destrucción de las ciudades situadas al sur del río Biobío por parte de los indígenas rebelados; así, también, en la narración de varios martirios y cautiverios que describe el autor, los cuales padecieron numerosos españoles, especialmente mujeres y niños; o en los diversos ataques que sufrieron los fuertes hispánicos ubicados en la zona del conflicto, todos detallados por González de Nájera. Sin perjuicio de lo anterior, el texto posee también una dimensión de tratado militar, ya que no solo intenta indagar en las razones del fracaso de las armas hispanas en Chile, sino que propone soluciones estratégicas para ganar la guerra, utilizando una terminología bélica y de arquitectura militar. Del mismo modo, el texto puede ser clasificado como un discurso esclavista, ya que buena parte de la solución militar al conflicto

\section{(c) (i) (2)}

La Revista Estudios es editada por la Universidad de Costa Rica y se distribuye bajo una Licencia Creative Commons Atribución-NoComercial-CompartirIgual 3.0 Costa Rica. Para más información envíe un mensaje a 
Especial: Naturaleza amena y naturaleza agreste en las letras hispánicas pasa, según el autor, por la esclavización de los indios de guerraii (esclavitud que de hecho existía ya en 1571, en plena gobernación de Melchor Bravo de Saravia, y se oficializó a través de una real cédula en 1608), para proponer que sean reemplazados por aborígenes africanos, considerados de mejor calidad o natural y más receptivos a la evangelización. Pero más interesante que todo lo anterior es la idea de que el texto de González de Nájera posee la estructura y finalidad de un arbitrio, esto es, una solución ingeniosa, fruto de un detenido estudio y reflexión, para un problema político-económico que se ha mostrado insoluble en el tiempo ${ }^{\mathrm{iii}}$. En este sentido podemos decir que el texto de Nájera es, en primer lugar, un interesante diagnóstico, hecho por un experto conocedor en la materia, de las razones del fracaso bélico de los españoles en el sur der Chile. Este arbitrio se sustenta en dos dimensiones: en la primera, la de desengaño, el autor se propone revelar la verdad sobre algunos mitos (y asimismo respecto a los obstáculos materiales y psicológicos) que impiden el éxito de las armas españolas en la guerra de Chile, entre los cuales destaca el originado por el imaginario épicomapuche inspirado en La Araucana de Ercilla. Así, el autor va desglosando cada uno de estos puntos, pasando revista, entre otros, a la ventaja geográfica que dan las inaccesibles montañas a los indígenas; la visión idealizada de la condición guerrera de los mapuche (incluso de su fortaleza física) por parte de los españoles; el fracaso de las campeadas y la inútil destrucción de las sementeras indígenas; la falsedad de los farautes o intérpretes mestizos que trabajan con los españoles; y, por sobre todo, la ingenuidad con que estos aceptan las fingidas paces ofrecidas por los indios. Con este diagnóstico en la mano González de Nájera propone en el texto la otra dimensión, la de reparo o remedio de los males de la guerra, indicando que todos estos obstáculos o desventajas deben ser enfrentados con decisión y profesionalismo, y con apoyo económico de la Corona: la desventaja geográfica mediante la construcción de una línea fortificada de fuertes españoles conectados entre sí en el margen del Biobío; la visión idealizada

\section{(c) (i)(2)}

La Revista Estudios es editada por la Universidad de Costa Rica y se distribuye bajo una Licencia Creative Commons Atribución-NoComercial-CompartirIgual 3.0 Costa Rica. Para más información envíe un mensaje a 
Especial: Naturaleza amena y naturaleza agreste en las letras hispánicas del guerrero mapuche debe dar paso a una visión real, porque este no es más fuerte ni diestro para la lucha que el español; asimismo, hay que prescindir de los farautes y rechazar los acuerdos de paz con los indígenas, por no ser estos confiables, y así sucesivamente. Esta dimensión de reparo se complementa con una serie de ejecuciones para ponerla en práctica: mejorar el estilo de hacer la guerra; prescindir de los esclavos indios y reemplazarlos por esclavos negros; proteger en mejor forma a los indios encomendados, vitales en la paz, y a los indios amigos, esenciales en la guerra, etc.

Dicho lo anterior, paso a referirme al propósito central de este trabajo, que es analizar la representación de la tierra de Chile en el texto: cómo la naturaleza es presentada, de entrada, en el segmento correspondiente a la historia natural y moral que plantea la obra de Nájera, y a la vez cómo esa misma naturaleza adquiere otros ribetes y connotaciones en la sección central del texto, la correspondiente al tratado militar o arbitrio.

Valga puntualizar que el destinatario de este texto es el Consejo Real, e incluso el propio rey Felipe III, del cual tenemos noticia que pudo leer un adelanto del texto en 1610 o 1611, y que de hecho tuvo a bien animar al autor a completarlo $^{\text {iv }}$. Po otra parte, y tal como indica Lucía Invernizzi, la representación de la tierra de Chile y sus gentes sigue en el texto inicialmente el tipo discursivo del obscurum genus ${ }^{\mathrm{v}}$, según el cual la situación de enunciación está determinada por la diferencia en la posesión del conocimiento sobre el objeto o materia del discurso: mientras el emisor, Alonso González de Nájera, es el poseedor del conocimiento, el receptor es quien carece de él, y, por consiguiente, el medio que permitirá llenar esa carencia va a ser el discurso del emisor ${ }^{\mathrm{vi}}$. La experiencia personal del autor, que combatió durante seis largos años en la guerra de Arauco primero como capitán, luego como sargento mayor y finalmente como maestre de campo, y su observación de la realidad, van a ser determinantes en la enunciación de este discurso, singularizando al hablante y determinando su relación con el 
Especial: Naturaleza amena y naturaleza agreste en las letras hispánicas receptor. En este contexto la tierra de Chile es, en primer lugar, un lugar deseado y ameno. Y es que todo el Libro primero, y en especial la Relación primera en él contenida, que lleva por título "Descripción del reino de Chile", y la Relación segunda, que denomina "Excelencias del reino de Chile", las dedica Nájera a mostrar la geografía natural de Chile, incluyendo la descripción de su territorio, sus climas y su naturaleza, así como la vida animal y vegetal y el mundo mineral. Esta Relación primera comienza con una descripción general, que se inicia con una caracterización breve de los indios, las dimensiones geográficas del reino, su montuosidad, las estaciones del año, los terremotos y las ciudades a uno y otro lado de la cordillera, para finalizar con una enumeración de sus ríos y puertos. Luego, en la Relación segunda, se nos presentan las excelencias de Chile; así, por ejemplo, el capítulo primero está dedicado a alabar su temple o clima:

Todo el reino de Chile es en general muy saludable, de lo cual tienen bien hecha esperiencia nuestros españoles, porque no están sujetos en él a tantas enfermedades ni a las largas y incurables que se padecen en Europa. No prueba la tierra a los españoles que llegan a aquel reino, y viven mucho más larga vida que los nacidos en él, y engendran más que en España (hasta los que por edad, según naturaleza, debieran ser inaptos para la generación); y las más mujeres son tan fecundas que las que en estos reinos fueron estériles de más de diez años de casadas, llegadas allá conciben cada año. Conviene aquel reino con las demás partes de las Indias en que no se sabe en él qué cosa sea peste (Desengaño, p. 167) ${ }^{\mathrm{vii}}$.

Del párrafo anterior cabe apuntar que las teorías sobre la generación que circulaban a comienzos del siglo XVII señalaban que la mujer, para ser fecunda, debía ser fría y húmeda. Según Juan Huarte de San Juan, "entre las tierras, aquellas son más fecundas y abundosas en fructificar que tienen más frialdad y humidad, como parece por experiencia considerando los lugares del Norte (Inglaterra, Flandes y Alemania) [...]. Y en tales tierras como estas, ninguna mujer, casándose, jamás dejó de parir, ni saben allá qué cosa es ser estéril" (Examen de ingenios, pp. 610-611). En general las mayores temperaturas se asociaban a una 
Especial: Naturaleza amena y naturaleza agreste en las letras hispánicas disminución de la fecundidad. Chile, según su latitud, tiene unas temperaturas equivalentes a las de esos países europeos, y por tanto sería un territorio proclive para engendrar.

A continuación, tras alabar la calidad y bondad de los alimentos o mantenimientos de la tierra, el autor ensalza su clima invernal: "Es tierra templadísima, de invierno tan poco riguroso que por maravilla nieva, y cuando sucede casi no cubre lo nevado la superficie de la tierra, do apenas permanece" (p. 169), así como el temple veraniego:

mañanas y tardes son de apacible frescor, como tierra que está contenida entre la nieve de la cordillera y la humedad del mar del Sur [...]; porque casi de ordinario respira el viento sur, que es todo lo que puede ser recreable, con suave olor de los floridos árboles y campos por donde pasa, especialmente en la primavera. [...] Las noches son más frescas que calurosas, porque con la ausencia del sol se dilata el frescor que dije de la frialdad de la nieve de la cordillera, por lo que el agua serenada se conserva y bebe fría todo el siguiente día [...]. Gózase de día y de noche de un cielo sereno y claro; y, en conclusión, aunque es largo el verano, dura comúnmente la fuerza dél cuatro meses, que es desde a mediado noviembre hasta a mediado marzo (170-171).

Nájera se refiere luego a los vientos, y prosigue su enumeración de las bondades del territorio y su naturaleza con las aguas, que configuran un verdadero locus amoenus:

son en estremo buenas y saludables, a causa de que las más corren por veneros de oro y ser de tierra tan montuosa, por donde se despeñan clarísimos arroyos de que por todas partes se reparten infinitas corrientes; demás de otras apacibles fuentes de particulares y varios nacimientos de lugares umbrosos y de notables vistas, así de riscos y peñascos como de acopadas y entretejidas arboledas (172).

En el capítulo dos de la Relación primera el autor vuelve a destacar la fertilidad de la tierra, afirmando "que paren comúnmente en él las ovejas y cabras a dos y a 
Especial: Naturaleza amena y naturaleza agreste en las letras hispánicas tres y a más crías" (173). Esta tierra deseada, tierra de promisión, "es [...] tan fértil y abundante de mantenimientos en todas las partes que se cultivan y benefician, que casi todos los de las tierras de paz y pobladas comen de balde, y por ninguna parte poblada se camina en las mismas tierras de paz que sea menester llevar dinero para el gasto del mantenimiento de personas y caballos. Por lo que, aunque hay gente pobre en aquella tierra, no hay ninguno mendigante" (174-175).

Prosigue el autor haciendo una apología de sus frutos y frutas, indicando que todas las frutas, legumbres y hortalizas llevadas de Europa se producen en Chile en gran cantidad, e incluso se exportan a Perú (175). Y no se olvida, por cierto, de inmortalizar un sabroso fruto autóctono de Chile, la frutilla, "tanto por su excelencia cuanto por ser sola natural de aquela tierra" (176) digna de que se haga de ella memoria:

sola una fruta [hay] que tienen de consideración original de aquella tierra, por estremo vistosa, sabrosa y olorosa y sana, aunque algo flemosa, a la cual se hace agravio con el diminutivo nombre que le dan, llamándola frutilla (por ser, como es, de tanta excelencia que puede muy bien competir en bondad con la más regalada fruta de España), cuya forma es de hechura de corazón; en grandeza son las más viciosas, y de jardines como huevos pequeños comunes y las más desmedradas campestres como nueces de todos tamaños. El color tienen unas blanco y otras rosado, y otras el uno y el otro. De comer son ternísimas, que se disuelven o deshacen en la boca, y a la digestión fáciles. No tiene esta frutilla corteza o cáscara que quitar; su superficie es unos puntos relevados a semejanza de madroños (pero no de su aspereza, porque son ternísimos y suaves). Y, finalmente, digo que no tienen hueso ni pepita ni cosa que desechar, y así, se come esta fruta entera, que cada una es un proporcionado bocado. Los indios hacen della vino y, curándola al sol, pasas, que son de buen comer. Nace esta fruta de una humilde yerbezuela que se planta para muchos años, a cuyas posesiones llaman los nuestros frutillares (176).

A continuación abunda el autor en la descripción de las viñas y vinos que produce el reino; sus hierbas y árboles; la sal mineral y marina y la miel que producen las 
Especial: Naturaleza amena y naturaleza agreste en las letras hispánicas abejas; los animales cuadrúpedos, la caza de montería, los pescados y mariscos, la caza de volatería y las aves domésticas, para terminar con las riquezas minerales del territorio. Todo este completo panegírico de la tierra de Chile, correspondiente a su dimensión de historia natural, se complementa en el texto con su dimensión de historia moral, cuyo objeto son los hombres y pueblos que la habitan. Así, en la Relación tercera del Libro primero, que el autor titula "Las verdaderas partes y calidades de los indios", va a describir pormenorizadamente los usos, costumbres, ritos, bailes y fiestas de los indígenas chilenos, desmitificando varios tópicos sobre los indios que el imaginario popular ha dado por sentados a partir de La Araucana de Alonso de Ercilla. En resumen, la descripción de la historia natural y moral de Chile configura el objeto deseado, hacia cuya posesión y dominio tiende la acción del agente. Pero esa posesión y dominio, como veremos, corre según el autor serio peligro debido a ciertos factores naturales y humanos, y aquí doy paso a la segunda parte de mi análisis. Pretendo ahora mostrar cómo esa tierra de promisión, controlada con dificultad y serias limitaciones por los españoles, y más desde el desastre de Curalaba, está a pique de perderse por la mala gestión de la guerra, y es entonces cuando la naturaleza cobra una nueva dimensión. Estamos ante la dimensión de espacio o territorio amenazante mencionada en el título de este trabajo, la cual plantea el autor como parte de la orientación deliberativa del discurso arbitrístico contenido en el texto. En este contexto el autor plantea en el Libro Segundo, previo a la exposición de un listado de desengaños, varios puntos que dan cuenta de claras ventajas que los indígenas poseen sobre los españoles en la guerra, a las cuales los peninsulares necesariamente debieran prestar atención si es que pretenden algún día vencer en ella. No parece casualidad que el primero de estos puntos, quizá para el autor el más importante, esté ligado justamente con la naturaleza del territorio que sirve de marco al conflicto. El epígrafe de este punto es sintomático, y reza así: "La guerra que hacen los indios a nuestros españoles con la gran 
Especial: Naturaleza amena y naturaleza agreste en las letras hispánicas

fortaleza de su tierra", y ya de entrada el autor llega a la conclusión, comprobada por él a lo largo de seis arduos años de campaña bélica en el sur de Chile, de que los indígenas, que componen un ejército bárbaro, rudimentario e indisciplinado, ante la indiscutible superioridad que daban a los españoles sus armas y caballos, tienen el gran mérito de contrarrestar esas ventajas de los hispanos aprovechándose de las características geográficas de su territorio:

Ninguna cosa les quedaba [a los indios] que les pudiese alentar a resolverse a ponerlo por obra sino solamente el seguro refugio y amparo que les ofrecía la gran fortaleza de su tierra, por ser poblada no solo de innumerables montes, sierras, valles y otras quebradas fragosísimas, pero de muchos y muy grandes ríos, ciénagas o pantanos, tales que cada cosa destas por sí sola se defiende; y es menester irla ganando, como dicen, palmo a palmo cuando no tuviera gente que se opusiera a defenderla. $Y$ como tienen esta calidad las tales tierras que en sus dificultosos pasos vale un hombre de los que los defienden por ciento de los que se los van a ganar, de aquí les nació, a mi parecer, a estos indios el atreverse a defender, junto con su deseada libertad, tierra que con su disposición tanto les convidaba y animaba a su defensa (Desengaño, p. 303).

La idea medular de Nájera, repito, es que los indígenas jamás se hubieran animado a rebelarse "si no les ayudara la gran fortaleza de su tierra" (303), así que podemos concluir que en la tierra tienen puesta su confianza, seguros de que en ella consiste su mayor ventaja: "Puesto que todas las veces que se han levantado, y se levantan cada día, es teniendo confianza en la segurísima guarida de sus montes y riscos" (304). Esa fortaleza y cercanía de su territorio, dice Nájera, les da la seguridad para actuar y ponerse a salvo sin previo aviso, y sin que la necesidad los obligue,

porque de balde se vuelven cada día a su natural casa, que para ellos es el paraíso terrenal y más fuerte que los más fuertes castillos de Europa, porque no se puede batir ni minar; pues mal se pueden batir montes ni minar ciénagas, ni se puede sitiar ni tomar por hambre, porque es tanta la abundancia de comidas, y tan buenas, que producen sus fértiles valles, 
Especial: Naturaleza amena y naturaleza agreste en las letras hispánicas montes y quebradas, que no tienen necesidad de esperar a ser bastecida de otras partes por vía de acarreto (304-305).

La misma geografía del territorio que en el Libro primero ha alabado como objeto deseado le sirve ahora al autor para mostrar otra cara, la de las serias dificultades que deben enfrentar los españoles en sus campañas militares debido a lo inexpugnable del territorio: "Pues decir que se les pueda dar escalada a sus montes y innumerables cerros, hallando en ellos entrada, ¿quién atinará tanto número de senderos, veredas, vados, quebradas y barrancos como en aquella tierra hay?" (305). Esta seguridad que da a los indígenas la fortaleza de su territorio se convierte casi en desvergüenza cuando los españoles entran en ella a hacer sus campañas:

Fuera de que es tan grande la seguridad que tienen los indios, hallándose en la aspereza de su tierra, que suele ir marchando nuestro campo por ella y ellos también acompañándolo a su vista por las altas cumbres de sus inexpugnables montes, tan seguros de nuestra gente y mosquetes como si estuvieran en las nubes. $Y$ aun muchas veces marcha nuestro campo por tales partes que va más sujeto a recebir daño dellos que ellos a peligro dél, porque, pasando por los forzosos caminos que van arrimados a las laderas y faldas de los encumbrados montes, dejan caer los enemigos grandes piedras y gruesos troncos de árboles que vienen rodando, adonde matan y quiebran piernas a soldados y caballos (306).

El autor se atreve a advertirle al rey que todo esfuerzo de hombres y recursos en la guerra de Arauco resultará inútil "supuesta la fortaleza de su tierra, por lo cual no ha de servir sino de perder gente y gastar su real hacienda, sin ganar sus vasallos alguna reputación" (307). Los ejemplos de esto pueden ser variados, dice el autor, pero por no cansar al lector solo menciona uno: cómo los indígenas aprovechan la fragosidad de la tierra para poner emboscadas a los españoles, como la tan efectiva de emboscarse junto a frutillares, los cuales resultan tan irresistibles para los hambrientos soldados que al encontrarse con

\section{(c) (i) (2)}

La Revista Estudios es editada por la Universidad de Costa Rica y se distribuye bajo una Licencia Creative Commons Atribución-NoComercial-CompartirIgual 3.0 Costa Rica. Para más información envíe un mensaje a 
Especial: Naturaleza amena y naturaleza agreste en las letras hispánicas ellos abandonan sus armas y se ponen a cosechar el delicioso fruto, para ser luego, en la indefensión más absoluta, atravesados por las lanzas indígenas (308309). Por cierto, la estimación de su tierra que según Nájera tienen los indios es superlativa:

Estiman sobremanera los indios sus tan propicios montes, por hallarlos tan cómodos para nuestra ofensa cuanto aparejados para su defensa; y como les deben toda su conservación, no dudo que si fueran gentiles, así como no guardan religión alguna, ya les hubieran atribuido alguna deidad, dedicándoles templos o otros simulacros que tuvieran en veneración (309310).

Incluso el autor apoyará sus afirmaciones recurriendo a la comparación con otros pueblos conquistados por los españoles en América del Sur, que habitan en tierras llanas, los cuales

con ser muchos más en número que los de Chile; más corpulentos, no menos armados y diestros en sus armas de flechas y bolas, y con estar sujetos también a españoles, a quien los de Chile rehúsan tanto el sujetarse, por los cuales no son poco trabajados ni muy exemptos de agravios, con todo esto encogen los hombros y sirven con humildad y obediencia no solamente sin rebelarse, pero sin haber dado jamás indicio dello; no porque no holgaran (como se puede muy bien presumir de gente sujeta) de romper el yugo y echar de sí la carga de la sujeción que tanto los lastima, pero la llanura de sus campos los obliga a sustentar esta paz y sosiego (310).

A continuación el autor ahonda en este punto ofreciendo ejemplos de otros pueblos que han basado su defensa en las características de la tierra, como son los cantones suizos y los moriscos de Granada, que se hicieron fuertes en la sierra de las Alpujarras. Para finalizar el punto, Nájera confirma la dimensión de serio y meditado arbitrio que posee el texto en este aspecto, el de la fortaleza de la tierra, como factor a considerar para desplegar las estrategias de guerra españolas, e incluso se da el trabajo de denunciar otros arbitrios por ridículos e inoperantes:

La Revista Estudios es editada por la Universidad de Costa Rica y se distribuye bajo una Licencia Creative Commons Atribución-NoComercial-CompartirIgual 3.0 Costa Rica. Para más información envíe un mensaje a 
No quiero dejar de referir dos graciosos pareceres que dio en escrito, en el Real Consejo de Indias, cierta persona de autoridad que acababa de llegar de Chile a España. El primero fue que sin ninguna duda se acabaría aquella conquista si los nuestros diesen en pegar fuego a los montes, pues, habiéndolos quemado, no ternían los enemigos dónde esconderse y, quedando descubiertos, los podrían matar a todos sin que quedase ninguno a vida. El otro arbitrio era que, supuesto que aquel reino es angosto y prolongado, que si se partiese nuestra gente en dos haces y con la una les tomasen las espaldas a los indios y con la otra la delantera, de modo que los cogiesen en medio, que vendrían a apretarlos de suerte que hiciesen en ellos una cruda matanza, y que los que de aquel aprieto escapasen por los lados, no hallando segura acogida atrás ni adelante, de fuerza habían de ir ahogarse en el mar del Sur o salir a la cordillera nevada (donde, por ser tierra fría y estéril, necesariamente habían de morir de frío y hambre) (313314).

\section{CONCLUSIÓN}

Muchos textos indianos no se limitan a describir las tierras descubiertas y conquistadas por España solo para cumplir con una ordenanza real; suelen también idealizar el espacio descrito como una forma de expresión de deseo o reclamo, con el objetivo de mostrar las bondades del territorio y de sus gentes y animar a la llegada de nuevos pobladores. Por otra parte, dichos textos también pueden presentar esa misma naturaleza como agreste, hostil e inhóspita, para así explicar las dificultades de la conquista española en esas tierras. Un excelente ejemplo de esta dicotomía se puede apreciar en la obra Desengaño y reparo de la guerra del reino de Chile (1614), de Alonso González de Nájera, texto curioso, mezcla de historia natural del territorio austral y de estudio antropológico de sus indígenas; cruce entre relación de sucesos, tratado de cautiverio y arbitrio o memorial para ganar la guerra de Arauco. El espacio -la tierra agreste e indómita - juega aquí un papel vital: por una parte el autor lo utiliza para hacer alarde de las bellezas del alejado territorio de Chile y promover su atractivo; por la

\section{(c) (i) (2)}

La Revista Estudios es editada por la Universidad de Costa Rica y se distribuye bajo una Licencia Creative Commons Atribución-NoComercial-CompartirIgual 3.0 Costa Rica. Para más información envíe un mensaje a 
Especial: Naturaleza amena y naturaleza agreste en las letras hispánicas otra muestra cómo lo agreste y salvaje de la tierra proporciona a los indígenas ventajas insuperables para vencer a los españoles en la inacabable guerra.

\section{BIBLIOGRAFÍA}

Donoso, M. (2017). Un documento inédito del siglo XVII: la Relación sumaria de servicios de Alonso González de Nájera, autor del Desengaño y reparo de la guerra del riii eino de Chile (1614). Anales de Literatura Chilena, 27, 97120.

Donoso, M. y Gaune, R. (2017). Alonso González de Nájera y su Desengaño y reparo de la guerra del Reino de Chile (1614). En Stefanie Massmann (coord.), Historia Crítica de la Literatura Chilena. Volumen I: la era colonial (pp. 191-200). Santiago: LOM Ediciones.

Faúndez, E. (2003). Los hombres sin rostro. Escritura y racismo en Desengaño y reparo de la guerra del Reino de Chile de Alonso González de Nájera. Atenea, 488, 117-134.

Gaune, R. (2017). Estudio preliminar. Alonso González de Nájera, un autor omnívoro. En González de Nájera, Alonso. Desengaño y reparo de la guerra del reino de Chile. Estudio biográfico y notas históricas y filológicas de Miguel Donoso Rodríguez; estudio preliminar y notas históricas de Rafael Gaune Corradi. Santiago: Universitaria.

González de Nájera, Alonso. Desengaño y reparo de la guerra del reino de Chile. Estudio biográfico y notas históricas y filológicas de Miguel Donoso Rodríguez; estudio preliminar y notas históricas de Rafael Gaune Corradi. Santiago: Universitaria. 2017.

Huarte de San Juan, Juan. Examen de ingenios para las ciencias. Ed. Guillermo Serés. Madrid: Cátedra. 1989.

Invernizzi, L. (1984). La representación de la tierra de Chile en cinco textos de los siglos XVI y XVII. Revista Chilena de Literatura, 23, 5-37.

Lausberg, H. (1975). Manual de Retórica Literaria. Trad. José Pérez Riesco. Madrid: Gredos. 3 vols.

\section{(c) (†) (-)}

La Revista Estudios es editada por la Universidad de Costa Rica y se distribuye bajo una Licencia Creative Commons Atribución-NoComercial-CompartirIgual 3.0 Costa Rica. Para más información envíe un mensaje a revistaestudios.eeg@ucr.ac.cr. 
Notas

' Agradezco al Fondo de Ayuda a la Investigación (FAl) de la Universidad de los Andes (Chile) su apoyo económico para participar en el congreso en el cual se originó esta publicación.

ii La guerra de Chile como guerra de exterminio propuesta por González de Nájera ha sido abordada por Faúndez, 2003.

iii Ver para este tema Donoso y Gaune, 2017, pp. 198-199 y especialmente Gaune, 2017, pp. 3745. En este momento el alumno de magíster en Historia de la Universidad de los Andes, Patricio Vergara, está elaborando una tesis sobre el Desengaño como arbitrio bajo mi dirección, la cual será defendida en en el segundo semestre de 2018.

iv Ver la Relación de méritos de González de Nájera, publicada en Donoso, 2017. La cita específica en p. 104.

v Ver Lausberg, Manual de Retórica Literaria, I, p. 115.

vi Tomo prestadas estas líneas de Invernizzi, 1984, p. 7.

vii Cito siempre el texto de Alonso González de Nájera por mi reciente edición en Editorial Universitaria, publicada en 2017.

La Revista Estudios es editada por la Universidad de Costa Rica y se distribuye bajo una Licencia Creative Commons Atribución-NoComercial-Compartirlgual 3.0 Costa Rica. Para más información envíe un mensaje a revistaestudios.eeg@ucr.ac.cr. 